\title{
Solid Fuel Decomposition Modelling for the Design of Biomass Gasification Systems
}

\author{
David Brown, ${ }^{\text {a* }}$ Tetsuo Fuchino, ${ }^{a}$ François Maréchal ${ }^{\mathrm{b}}$ \\ ${ }^{a}$ Tokyo Institute of Technology, S1 Bldg, \#363, 2-12-1 Ookayama, Meguro Tokyo Japan \\ ${ }^{b}$ Ecole Polytechnique Fédérale de Lausanne, LENI-ISE-STI-EPFL, Station 9, CH-1015, \\ Lausanne Switzerland
}

\begin{abstract}
A novel equilibrium reaction modelling approach is proposed for the efficient design of biomass gasifiers. Fuels and chars are defined as pseudo species with properties derived from their ultimate analyses; tars as a subset of known molecular species and their distribution determined by equilibrium calculations. Non-equilibrium behaviour for gas, tar, and char formation is explained by reaction temperature differences for a complete set of stoichiometric equations. A nonlinear regression, with an artificial neural network $(\mathrm{NN})$, relates changes in temperature differences to fuel composition and operational variables. This first principles approach, illustrated with fluidised bed reactor data, improves the accuracy of equilibrium calculations, and reduces the amount of required data by preventing the $\mathrm{NN}$ from learning atomic and heat balances.
\end{abstract}

Keywords: biomass, tar, equilibrium temperature differences, neural networks.

\section{Introduction}

Biomass gasification is of interest for combined heat and power production (CHP), be it for onsite conversion and cogeneration, or for the production of synthetic fuels such as methane (e.g. Duret et al, 2005). A major impediment to CHP remains equipment fouling problems related, namely, to the production of a wide array of condensable species commonly termed tar. In this respect, reaction modelling is a challenging task, because of the difficulty of identifying and quantifying heavier products, and the lack of thermophysical properties for a variety of feedstocks, chars, and tars. In addition, the quantity and the nature of tars vary according to several factors such as reactor temperature and pressure (Shafizadeh, 1982; Evans and Milne, 1987), the nature and ratio of oxidising gases (Kinoshita et al, 1994), the nature of biomass feedstocks (Fagbemi et al, 2001) especially the catalytic effect of their inorganic content (Shafizadeh, 1982), and even the types of gasifiers (Buekens and Schoeters; 1985). These issues have an impact on choices between design alternatives that affect the overall efficiency of process design. Indeed, it is important to reliably estimate tar distributions to determine product condensation points in order to design the appropriate contaminant removal configuration. To meet this end, we are developing a simple modelling approach that broadens the applicability of chemical equilibrium calculations. The approach relies on equilibrium reaction temperature difference parameters, derived from a database of standardised fuel analyses and quantified product compositions deduced from pilot gasifier measurements obtained under different operating conditions. These parameters serve as an estimator of kinetic, catalytic, and fluid dynamic effects that are not explained by equilibrium modelling.

\footnotetext{
* Author to whom correspondence should be addressed: brown@chemeng.titech.ac.jp
} 


\section{Description and illustration of modelling approach}

The approach is illustrated with air gasification data from pilot circulating fluidised bed reactors of similar dimensions operated at atmospheric pressure (García-Ibañez et al., 2004; van der Drift et al., 2001). The operational variables of the database are feedstock compositions, gasifying air equivalence ratios (ER), and reaction temperatures (T). Upon verifying mass balances, the data of van der Drift et al. (2001) (set B) was kept for modelling, and the data of García-Ibañez et al. (2004) (set A) for model validation.

\subsection{Generating additional compositional data from a non-stoichiometric model}

As it would be costly if not impossible to separately quantify each tar specie, in the first step of the approach, quantity and elemental composition measurements of the total tars produced, are used to calculate a distribution for a subset of unmeasured cyclic species that typically result from biomass gasification (Evans and Milne, 1987). This is done with a non-stoichiometric (NS) equilibrium model, i.e. under the constraint of the reaction mixture's elemental composition (Smith and Missen, 1982). The assumption is that experimental measurements have precedence over chemical equilibrium. The Gibbs free energy of the system is minimised by SQP optimisation under individual measurement constraints for major species, and the total elemental stoichiometry of tar (and other lumped) species. Another assumption, to avoid convergence problems that arise when considering phase equilibrium, and that is acceptable at low and atmospheric pressures (Evans and Milne, 1987), is that the tar species form entirely in the gas phase. The molecular species are listed in Table 1. Species of sets A and B are on the first line, and species of which the formation was modelled on the following lines. There are two types of lumped species in set B: tars and remaining hydrocarbons (HC). The species in italics were finally withdrawn after preliminary NS calculations, because their formation is not thermodynamically favoured. The model enables estimating distributions of a considerably large subset of additional tar (24), and HC (10) species, that would otherwise not appear after equilibrium calculations. Feedstocks and chars are modelled as pseudo species with unit carbon formulas determined from their dry ash free ultimate analyses; standard enthalpies of formation by use of Thornton's (1917) rule with the constant of Patel and Erickson (1981); standard entropies of formation from the correlation of Battley and Stone (2000); and solid specific heat capacities by adapting a modified partition function (Merrick, 1983) to a Kopp's rule.

Table 1. Species quantified in references and species added for equilibrium calculations

\begin{tabular}{|c|c|c|}
\hline A \& B & $\mathrm{N}_{2} \mathrm{H}_{2} \mathrm{H}_{2} \mathrm{O} \mathrm{CO}_{2} \mathrm{CO} \mathrm{CH}_{4} \mathrm{C}_{2} \mathrm{H}_{4} \mathrm{C}_{2} \mathrm{H}_{6}$ & $\mathrm{C}_{6} \mathrm{H}_{6} \mathrm{C}_{7} \mathrm{H}_{8} \mathrm{C}_{8} \mathrm{H}_{10}{ }^{(4)} * \mathrm{NH}_{3} \mathrm{H}_{2} \mathrm{~S} \mathrm{HCl}$ \\
\hline & \multirow{3}{*}{\multicolumn{2}{|c|}{ 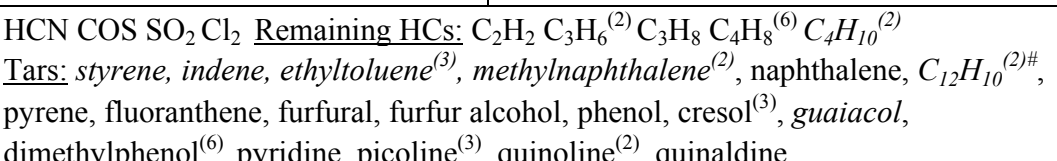 }} \\
\hline & & \\
\hline $\begin{array}{l}\text { gases } \\
\& \text { tars }\end{array}$ & & \\
\hline
\end{tabular}

Notes. ${ }^{(n)}$ number of isomers specs * "xylene" in B, added ethylbenzene "biphenyl \& acenaphthene

\subsection{Formulation of a stoichiometric model for gasification}

Secondly, as in Duret et al. (2005), a stoichiometry is defined, and fitted to the product distribution by letting reaction equilibrium temperatures vary from the measured gasification temperature. A complete stoichiometry is generated by writing the molecule and element formula matrix in its reduced row echelon form (Smith and Missen, 1982),

$\mathbf{A}=\left(\mathbf{I}_{\mathbf{C}} \mathbf{Z}\right)$, from which $\mathbf{N}=\left(-\mathbf{Z} \mathbf{I}_{\mathbf{F}}\right)^{T}$ is deduced 
Where $\mathrm{C}$ is usually the number of atomic elements, and $\mathrm{F}$ the number of independent stoichiometric equations (usually the difference between species and elements). The temperature differences are therefore deduced by considering that the compositions resulting from the NS model are constant and by solving the non linear problem,

$$
\left(\frac{\partial G}{\partial \xi_{j}}\right)_{T, P}=\sum_{i=1}^{N} v_{i j} \mu_{i j}\left(T+\Delta T r_{j}, P, \mathbf{n}\right)=0 \quad \forall j=1, \ldots, F
$$

Eq. (2) implies that each stoichiometric equation is generated with the same molecular specie for each element. In our example, there are 47 independent equations derived from the six constitutive species (i.e. $\mathrm{C}, \mathrm{H}, \mathrm{O}, \mathrm{N}, \mathrm{S}, \mathrm{Cl}$ ) of the system. We have considered using either one of the two following general equation formulations analogous to $\mathrm{H}_{2} \mathrm{O}$-Eq. (3)- or $\mathrm{CO}_{2}$-Eq. (4)- gasification,

$$
\begin{aligned}
& \mathrm{C}_{\mathrm{n}} \mathrm{H}_{\mathrm{m}} \mathrm{O}_{\mathrm{p}} \mathrm{N}_{\mathrm{q}} \mathrm{S}_{\mathrm{r}} \mathrm{Cl}_{\mathrm{t}}+(\mathrm{n}-\mathrm{p}) \mathrm{H}_{2} \mathrm{O} \rightarrow \mathrm{nCO}+\left(\frac{\mathrm{m}}{2}+\mathrm{n}-\mathrm{p}-\frac{3}{2} \mathrm{q}-\mathrm{r}-\frac{\mathrm{t}}{2}\right) \mathrm{H}_{2}+\mathrm{qNH}_{3}+\mathrm{rH}_{2} \mathrm{~S}+\mathrm{tHCl} \\
& \mathrm{C}_{\mathrm{n}} \mathrm{H}_{\mathrm{m}} \mathrm{O}_{\mathrm{p}} \mathrm{N}_{\mathrm{q}} \mathrm{S}_{\mathrm{r}} \mathrm{Cl}_{\mathrm{t}}+(\mathrm{n}-\mathrm{p}) \mathrm{CO}_{2} \rightarrow(2 \mathrm{n}-\mathrm{p}) \mathrm{CO}+\left(\frac{\mathrm{m}}{2}-\frac{3}{2} \mathrm{q}-\mathrm{r}-\frac{\mathrm{t}}{2}\right) \mathrm{H}_{2}+\mathrm{qNH}_{3}+\mathrm{rH}_{2} \mathrm{~S}+\mathrm{tHCl}
\end{aligned}
$$

$\Delta \operatorname{Tr}_{\mathrm{j}}$ ranges and averages obtained with both stoichiometric formulations, for the twelve samples of set $\mathrm{B}\left(\mathrm{NH}_{3}\right.$ formation, the water gas shift and methane reforming reactions, naphthalene, anthracene and char formation) are indicated in Table 2. Duret et al. (2005) reported similar values for the average $\Delta \operatorname{Tr}_{j}$ of the shift and methane reforming reactions (40 and $-224 \mathrm{~K}$ respectively). However, results indicate that the spread of the

\begin{tabular}{|c|c|c|c|c|c|c|c|c|c|c|c|c|c|c|c|}
\hline React. & $\mathrm{mn} \Delta \mathrm{T}$ & $\mathrm{mx} \Delta \mathrm{T}$ & av $\Delta \mathrm{T}$ & $\mathrm{H}$ & $\mathrm{C}$ & $\mathrm{N}$ & $\mathrm{O}$ & $\mathrm{S}$ & $\mathrm{Cl}$ & $\mathrm{FC}$ & V & $\mathrm{hm}$ & As & $\mathrm{T}$ & ER \\
\hline \multicolumn{16}{|c|}{ Eq. (3) stoichiometry } \\
\hline $\mathrm{NH}_{3}$ & -657 & -482 & -565 & 1. & 0. & 16. & 1. & 51. & 32. & 66. & 0. & 50. & 0. & 21. & 5. \\
\hline Shift & -120 & 939 & 159 & 1. & 1. & 31. & 3. & 87. & 40. & 86. & 1. & 5. & 1. & 97. & 0. \\
\hline Refo. & -367 & -230 & -281 & 34. & 39. & 2. & 55. & 34. & 5. & 53. & 39. & 44. & 32. & 6. & 3. \\
\hline Naph. & -494 & -383 & -428 & 43. & 48. & 3. & 61. & 38. & 3. & 62. & 46. & 41. & 39. & 5. & 4. \\
\hline Anth. & -440 & -299 & -378 & 95. & 79. & 12. & 74. & 66. & 40. & 12. & 91. & 54. & 90. & 41. & 48. \\
\hline Char & -650 & -568 & -605 & 69. & 79. & 2. & 84. & 27. & 1. & 68. & 70 . & 70. & 65. & 1. & 13. \\
\hline
\end{tabular}
shift reaction is high. Also, most $\Delta \operatorname{Tr}_{\mathrm{j}}$ spreads are larger for Eq. (3) than for Eq. (4).

Table 2. $\Delta \operatorname{Tr}_{j}$ averages and ranges \& linear correlation coefficient $\mathrm{p}$-values for certain reactions

Eq. (4) stoichiometry (same stoichiometry as above for $\mathrm{NH}_{3}$ and water gas shift reactions)

\begin{tabular}{llllllllllllllll}
\hline Refo. & -299 & -213 & -248 & 67. & 74. & 3. & 88. & 13. & 6. & 46. & 74. & 92. & 65. & 0. & 19.
\end{tabular}

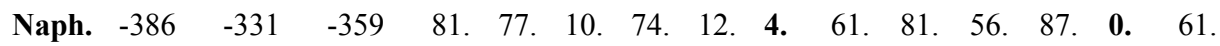

$\begin{array}{llllllllllllllll}\text { Anth. } & -371 & -249 & -312 & 46 . & 64 & 38 & 31 . & 56 . & 70 . & 12 . & 36 & 77 . & 49 . & 35 . & 64 .\end{array}$

$\begin{array}{llllllllllllllll}\text { Char } & -536 & -480 & -509 & 56 . & 49 & \text { 12. } & 56 . & 12 . & \text { 3. } & 74 . & 58 . & 38 . & 61 . & \text { 0. } & 92 .\end{array}$

Notes. mn: minimum; mx: maximum; av: average; FC: fixed carbon; VM: volatile matter; hm: humidity; ER: equivalence ratio. Units. Temperature differences [K], p-values [\%]

\subsection{Nature of correlation between temperature differences and independent variables}

$\mathrm{The} \Delta \mathrm{Tr}_{\mathrm{j}}$ are strongly dependent of fuel composition and operating condition variables. However, the validity of the temperature difference model relies on the assumption that 
certain $\Delta$ Trj parameters are not affected by changes in processing conditions. Hence, sample correlation coefficients between each $\Delta \operatorname{Tr}_{j}$ and input variables have been computed to determine whether any uncorrelated variables exist. Linear and nonlinear correlations (e.g. logarithms, exponentials, and inverses) of input variables have been tested. The p-values of the linear correlation coefficients are also in Table 2. This Fisher distribution variable is the probability of randomly obtaining a correlation as large as the one observed. $\mathrm{T}$ and ER (both independent of fuel properties) are of particular interest. At a $10 \%$ significance level (single digit percentages in bold), it appears that,

- The $\Delta \mathrm{Tr}_{\mathrm{j}}$ are independent of $\mathrm{T}$ for the shift and ammonia $\left(2 \mathrm{NH}_{3} \leftrightarrow 3 \mathrm{H}_{2}+\mathrm{N}_{2}\right)$ reactions, and of ER for most other equations of Eq. (4). (i.e. $\mathrm{CO}_{2}$ ) stoichiometry.

- Fixed carbon is uncorrelated to all reactions; humidity, volatile matter and ash are correlated to the $\mathrm{NH}_{3}$ and shift reactions, as is the ash content to tar formation.

- The $\Delta \operatorname{Tr}_{\mathrm{j}}$ are strongly correlated to major elements $\{\mathrm{C} \mathrm{H} \mathrm{O}\}$ for the $\mathrm{NH}_{3}$ and shift reactions, minor elements $\{\mathrm{N} \mathrm{Cl}\}$ for most other reactions; and weakly to $\mathrm{N}$ for $\mathrm{NH}_{3}$ formation, and $\{\mathrm{C} \mathrm{H} \mathrm{S}\}$ for $\mathrm{HC}$, tars, and char reactions (exponential of inverse test).

\subsection{Modelling the temperature difference using artificial neural networks}

$T$ The $\Delta \operatorname{Tr}_{j}$ represent a relationship between several operational variables, that was not physically modelled, but approximated instead by a nonlinear regression. Multilayer feed forward artificial neural network $(\mathrm{NN})$ models have been used to represent the variation of each $\Delta \operatorname{Tr}_{j}$ as a function of the operational variables. Having established that strongly correlated variables are not the same for each reaction, a fully connected two layer NN is defined for each reaction. Each NN has a number of hidden sigmoid nodes that vary in function of the number of inputs, and a single linear node as the output. As suggested by Sarle, (1994) direct input/output layer connections are added to account for the lower order effects noted in Table 2. The problem formulation is,

$$
\min _{b, w} \sum_{s}^{m s}\left(\Delta T r_{j s}-\Delta \hat{T} r_{j s}\right)^{2}
$$

with,

$$
\Delta \hat{T} r_{j s}=b_{j}+\sum_{h=1}^{m h} w_{h j}\left(1+\exp \left(b_{h}+\sum_{f=1}^{m f} w_{f h} x_{f}\right)\right)^{-1}+\sum_{f=1}^{m f} w_{f j} x_{f}
$$

The problem is solved with standard backpropagation of errors to the hidden layer. Incomplete target vectors are assigned a null error for unmeasured target values.

\subsection{Network training and validation}

NNs can be estimators of arbitrary square-integrable functions (White, 1990), however their major drawback is the high dimensionality of their weight space, which implies the risk of obtaining poor interpolations between training points. Generally speaking, large data samples, i.e. a number a least superior to the number of weights and biases, are needed to obtain good interpolation properties (termed generalisation). With the twelve observations of set B, as indicted in Table 3. (in bold), there would be fewer parameters than observations only in single input networks, or with two variables and a single hidden node per variable. Obviously a larger data sample would be preferable, but it can be costly in practice to generate a sample of several hundred or thousands of entries. 


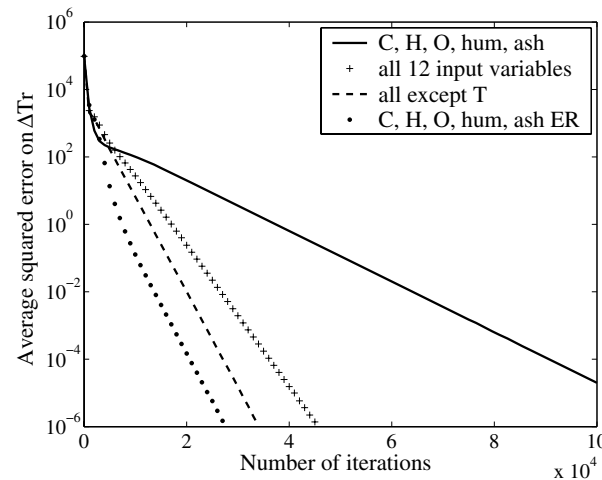

Figure 1. Impact of input vars. on shift reaction

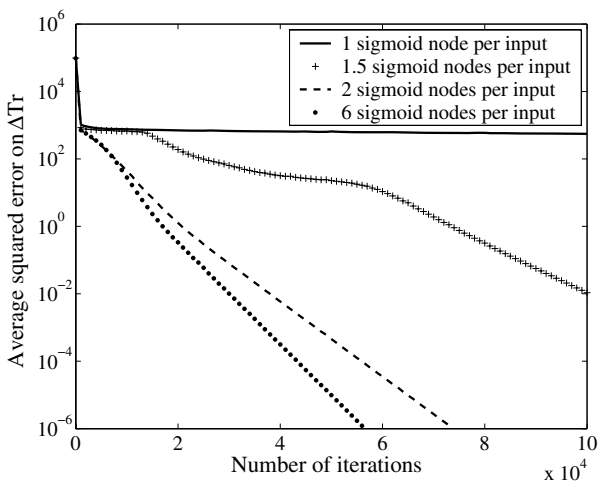

Figure 2. Size of hidden layer (Anthracene)

Preliminary validation tests and results from the literature allow reducing the number of input variables and of hidden nodes per input. Fixed carbon (FC) and volatile matter (VM) can be considered as dependent variables because the $\mathrm{FC}$ ratio is proportional to both the $\mathrm{H} / \mathrm{C}$ and $\mathrm{O} / \mathrm{C}$ ratios (van Krevelen, 1950; Jenkins et al, 1998). We used the preliminary correlation analysis (Table 2.) to further reduce the number of model parameters. For instance, Fig. 1. shows that, for the shift reaction, in concordance with p-value tests, error minimisation is more difficult with apparently uncorrelated inputs (but even more without ER). Fig. 2. indicates that to correlate the (Eq. (4)) set of $\Delta \operatorname{Tr}_{j}$ of anthracene, there can be less than two hidden nodes per input, but that a single node is insufficient. The results obtained from the training set $\mathrm{B}$ have been assessed with another set of data (set A). The quality of generalisation for certain reactions is given in Table 4 . as the relative error between modeled and calculated $\Delta \operatorname{Tr}_{j}$. Generalisation is particularly poor for the shift reaction while it is better for char and $\mathrm{HC}$ reactions.

Table 3. Number of parameters (w \& b) per input variables and hidden nodes per input.

\begin{tabular}{lllllllllllll}
\hline $\mathrm{h}$ nodes/vars. & 1 & 2 & 3 & 4 & 5 & 6 & 7 & 8 & 9 & 10 & 11 & 12 \\
\hline 1 & $\mathbf{5}$ & $\mathbf{1 1}$ & 19 & 29 & 41 & 55 & 71 & 89 & 109 & 131 & 155 & 181 \\
2 & $\mathbf{8}$ & 19 & 34 & 53 & 76 & 103 & 134 & 169 & 208 & 251 & 298 & 349 \\
3 & $\mathbf{1 1}$ & 27 & 49 & 77 & 111 & 151 & 197 & 249 & 307 & 371 & 441 & 517 \\
\hline
\end{tabular}

Table 4. Errors on calculated (Eq. (4) stoichiometry) and interpolated (100000 iterations) $\Delta \operatorname{Tr}_{\mathrm{j}}$

\begin{tabular}{llllllll}
\hline Reaction & Input variables & h/vars. & av. B & A.1 & A.2 & A.3 & A.4 \\
\hline $\mathbf{N H}_{3}$ & $\{\mathrm{C}, \mathrm{H}, \mathrm{O}$, hum, ash, ER $\}$ & 3 & $0.000 \%$ & $-17 \%$ & $-17 \%$ & $-22 \%$ & $-19 \%$ \\
Shift & $\{\mathrm{C}, \mathrm{H}, \mathrm{O}$, hum, ash, ER $\}$ & 3 & $0.77 \%$ & $-150 \%$ & $-79 \%$ & $-58 \%$ & $-50 \%$ \\
Shift & All 12 input variables & 6 & $0.000 \%$ & $-71 \%$ & $-125 \%$ & $-131 \%$ & $-123 \%$ \\
Reform. & 10 vars. (all but FC\&VM) & 6 & $0.020 \%$ & $29 \%$ & $34 \%$ & $15 \%$ & $29 \%$ \\
Char & 10 vars. (all but FC\&VM) & 3 & $0.002 \%$ & $14 \%$ & $8.1 \%$ & $-0.1 \%$ & $6.4 \%$ \\
\hline
\end{tabular}

\section{Conclusion and recommendations}

A reaction model has been developed for the rapid computation of product compositions of biomass gasification. An NS equilibrium model based on total tar measurements, is first applied to estimate the distribution of tar species. The product distribution is then formulated as a stoichiometric equilibrium model with reaction equilibrium temperature 
differences. Although certain temperature differences appear to be uncorrelated to independent variables such as $\mathrm{T}$ and $\mathrm{ER}$, other temperature differences are strongly correlated to these variables. Since there is no clear evidence of any single or characteristic relationship between operational variables and temperature differences, the use of an appropriately designed $\mathrm{NN}$ appears as a solution to parameterise the reaction temperature differences, even with a data sample of limited size. Future improvements to generalisation could include adding data samples and/or additional constraints to improve the smoothness of the NN regression, e.g. weight decay (Krogh and Hertz, 1991), and using prediction intervals (De Veaux et al, 1998).

\section{Nomenclature}

$\mathrm{a}_{\mathrm{ik}}$ or $\mathbf{A}$ : number of atomic elements $\mathrm{k}$ in molecular specie $\mathrm{i}$, and element molecule formula matrix b: network biases

C: rank of formula matrix (usually $\mathrm{C}=\mathrm{M}$, the number of atomic elements)

F: number of stoichiometric degrees of freedom (of linearly independent equations)

G: Gibbs function $[\mathrm{kJ} / \mathrm{kmol}]$; $\quad$ I: identity matrix

$\mathrm{n}_{\mathrm{i}}$ or $\mathbf{n}$ : quantity of molecular specie $\mathrm{i}$ (or of all species) at equilibrium [kmol]

$\mathrm{N}$ : number of molecular species; $\quad \mathbf{N}$ : complete stoichiometric matrix

$\mathrm{m}$ : number of terms in a sum; $\quad$ M: number of elements

$P$ : reaction pressure $[\mathrm{kPa}] ; \quad \mathrm{R}$ : gas constant $[\mathrm{kJ} / \mathrm{kmol}-\mathrm{K}] ; \quad \mathrm{T}$ : reaction temperature $[\mathrm{K}]$

$\Delta \operatorname{Tr}_{\mathrm{j}}$ : temperature difference between equilibrium and actual composition for reaction $\mathrm{j}[\mathrm{K}]$

$\operatorname{tar} \&$ tars: reconciled measurement of tar concentration and subset of tar species

$\mathrm{x}_{\mathrm{f}}$ : input variable f to network; $\quad$ w: network weight

$\mathbf{Z}$ : matrix of dimension $\mathrm{C} \times \mathrm{F}$ when the only compositional constraint are element abundances

Greek letters $\mu$ : chemical potential $[\mathrm{kJ} / \mathrm{kmol}] ; v$ : stoichiometric coefficient; $\xi_{j}$ : extent of reaction $\mathrm{j}$

Indexes $\quad f:$ input variables to network; i: molecular species; $\quad$ I: isomers

h: hidden nodes; j: chemical reactions; $\quad$ k: atomic elements; $\quad$ s: observations

\section{References}

E.H. Battley and J. R. Stone, 2000. Thermochimica Acta., 349, 153.

A.G. Buekens and J.G. Schoeters 1985. in Fundamentals of Thermochemical Biomass

Conversion, R.P Overend, T.A Milne and L.K Mudge eds., Elsevier Applied Science (Ch. 35).

R.D. De Veaux, J. Schumi, J. Schweinsberg, L.H. Ungar, 1998. Technometrics., 40, 273.

A. Duret, C. Friedli and F. Maréchal, 2005. Journal of Cleaner Production., 13-15, 1434.

R.J. Evans and T.A. Milne, 1987. Energy \& Fuels., 1, 123.

L. Fagbemi, L. Khezami, R. Capart, 2001. Applied Energy., 69, 293.

P. García-Ibañez, A. Cabanillas and J.M. Sánchez, 2004. Biomass \& Bioenergy., 27, 183.

B.M. Jenkins, L.L. Baxter, T.R. Miles Jr. and T.R. Miles, 1998. Fuel Proc. Technol., 54, 17.

C.M. Kinoshita, Y. Wang, J.Zhou, 1994. J. Analytical and Applied Pyrolysis., 29, 169.

A. Krogh and J.A. Hertz, 1991. Neural Information Processing Systems., 4, 950.

D. Merrick, 1983. Fuel., 62, 535.

S.A. Patel and L. E. Erickson, 1981. Biotechnology \& Bioengineering., 23, 2051.

W.S. Sarle, 1994. Proc. 19th annual SAS users group international conference., 1538.

F. Shafizadeh, 1982. Journal of Analytical and Applied Pyrolysis., 3, 283.

W.R. Smith and R. Missen, 1982. Chemical Reaction Analysis: Theory and Algorithms., USA.:

John Wiley and Sons (Ch. 2 \& Ch. 6)

W.M. Thornton, 1917. Phil Mag., 33, 196.

A. van der Drift, J. van Doorn and J.W. Vermeulen, 2001. Biomass \& Bioenergy., 20, 45.

D.W.van Krevelen, 1950. Fuel., 29, 269.

H. White, 1990. Neural Networks., 3, 535.

Acknowledgements Funding provided by the Ministry of Education, Culture, Sports, Science and Technology of Japan is gratefully acknowledged. 